\title{
The need for horticulturist expertise in plant conservation: challenges and opportunities
}

\author{
Paul P. Smith
}

\begin{abstract}
As many as 40 per cent of the world's plant species are currently threatened with extinction. Botanic gardens have an important role to play in restoring habitats and supporting plant species recovery in situ. Specialist horticultural skills are essential for proactive plant conservation and management. However, there are a number of impediments to deploying horticultural expertise where it is needed the most, including a lack of information about which species and recovery programmes need expertise, where that expertise can be found, and institutional or practical issues such as availability of time and funding. In this paper, the author presents details on tools and resources developed by Botanic Gardens Conservation International designed to engage and support the participation of horticulturists in plant conservation.
\end{abstract}

\section{Introduction}

According to the recent report produced by the Royal Botanic Gardens, Kew on the state of the world's plants (Antonelli et al., 2020), as many as 40 per cent of plant species are threatened with extinction. The main driver for plant extinctions is land use change, particularly for agriculture, forestry and urbanisation. Transformed human-managed landscapes have become the norm (Hooke et al., 2012), and these will only increase as human populations increase. What this means for all the species that currently occupy these transformed landscapes - or in some cases that are just clinging on to them - is that they face a series of challenges that are human related: not just clearing of vegetation, but also over-exploitation, introduction of new pests and diseases, invasive alien species and, increasingly, climate change (Venter et al., 2016). Consequently, proactive conservation and management are needed if we wish to conserve species diversity. Why is plant diversity important? Perhaps the most compelling reason is that we need plants to solve most of humanity's major challenges. For our food security, we need a wider range of crops to enable us to adapt to a changing climate, new pests and diseases, and increasing human populations. To address water scarcity, we need to restore catchment forests and to plant trees that do not use water in dry areas. For sustainable energy, we need biomass and biofuels. For human health, much of the world's population relies on traditional medicines and pharmacopoeia based largely on plants. For biodiversity loss itself, if we want to conserve charismatic mammals like the tiger or the panda, then of course we need to conserve the habitats and the plants at the base of the trophic pyramid. Those same plants provide us

${ }^{1}$ Paul Smith is Secretary General (CEO) of Botanic Gardens Conservation International. Address: Descanso House, 199 Kew Road, Richmond, Surrey, TW9 3BW, UK.

Email: Paul.smith@bgci.org 
with ecosystem services, including water, erosion control, oxygen and options for both mitigating and adapting to climate change. In short, plant diversity enables human innovation adaptation and resilience, and the more diversity we can conserve, the more options we will have in the future (Smith et al., 2011). In addition, many would argue on religious, philosophical or spiritual grounds that the organisms we share the planet with have an equal right as humans to exist. For example, Pope Francis in his Encyclical (2018) says, 'It is not enough ... to think of different species merely as potential "resources" to be exploited, while overlooking the fact that they have value in themselves. Each year sees the disappearance of thousands of plant and animal species which we will never know, which our children will never see, because they have been lost forever. The great majority become extinct for reasons related to human activity. Because of us, thousands of species will no longer give glory to God by their very existence, nor convey their message to us. We have no such right.'

\section{The role of botanic gardens and specialist horticulture}

So what is the role of botanic gardens in conserving and managing plant diversity? Firstly, we grow at least 30 per cent of all known higher plant species (Mounce et al., 2017), and this puts us right at the top of the league when it comes to horticulture. In comparison, foresters and farmers grow a very narrow range of plant genetic diversity. Secondly, we grow plants right across the taxonomic array. Furthermore, we can find plants using herbarium records, and we can identify them once we are in the field. We conserve them in seed banks, in our living collections and in situ (many botanic gardens manage nature reserves), and we are increasingly restoring habitats and reintroducing species. Botanic gardens themselves are diverse landscapes for ecosystem services, delivering mental and physical health benefits (Smith \& HarveyBrown, 2018). We could say that there is no technological reason why any plant species should become extinct (Smith et al., 2011). With the array of horticultural techniques available to us and if we can get to a species in time, then there is a very good chance that we can conserve or grow plants and prevent them from becoming extinct.

\section{Creating a cost-effective global system for plant conservation}

Fig. 1 shows a map of the world's botanic gardens derived from the GardenSearch database of Botanic Gardens Conservation International (BGCl), with around 3,000 gardens listed. As can be seen from the map, around 85 per cent of the world's botanic gardens are in the northern hemisphere and comparatively few are in the tropics where plant diversity is concentrated (Mounce et al., 2017). So although we have an estimated 60,000 botanical experts within the BGCI network alone, they are skewed towards the north, and one of our big challenges is how to get that expertise and knowledge and share it with gardens in the south, particularly in the tropics, in order to solve some of these species-related problems. As an example, $\mathrm{BGCl}$ is leading the Global Tree Assessment (GTA) (Newton et al., 2015), which aims to assess the conservation status of all the world's 60,000 tree species. We are on track to do that, and already we know that there are more rare tree species than there are common tree species - 58 per cent of tree species are endemic to a single country (Beech et al., 2017), and around 


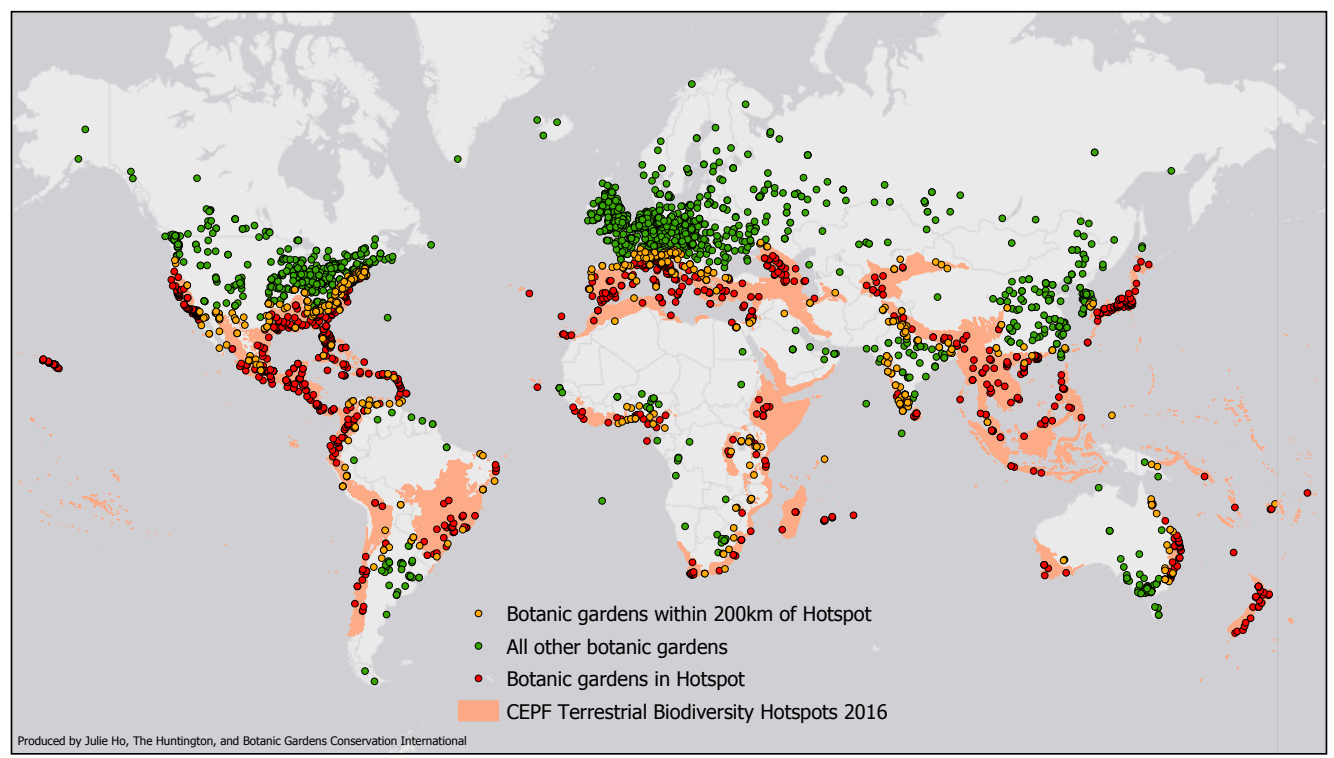

Fig. 1 Map of the world's botanic gardens (2019) from BGCl's GardenSearch database (https://tools.bgci.org/garden_ search.php) compared to Critical Ecosystem Partnership Fund biodiversity hotspots. Map: BGCI.

40 per cent of tree species are threatened with extinction (Malin Rivers, pers. comm.). So far, the GTA has identified about 2,400 species that are critically endangered, i.e. about to become extinct, 450 of which have fewer than 50 individuals remaining in the wild (IUCN, 2020). Given that we have around 3,000 botanic gardens and thousands of experts, then surely this is something that we can tackle systematically in a rational, cost-effective way (Smith, 2016).

Examples of species that are on the brink of extinction include Hyophorbe amaricaulis in Mauritius (Fig. 2) - known as 'the loneliest tree in the world'. This single remaining specimen in Curepipe Botanical Garden is 150 years old, and as far as we know is the only one of its kind. It is diseased and probably will not survive much longer. So far, attempts to propagate it have failed (Douglas, 1987). Another example from the International Union for Conservation of Nature (IUCN) Red List

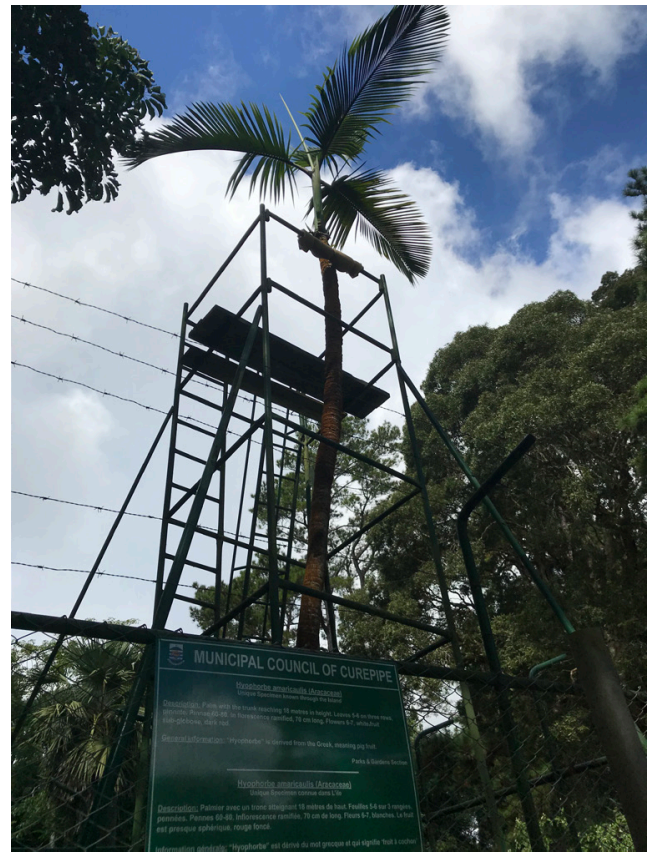

Fig. 2 Hyophorbe amaricaulis, 'the loneliest tree in the world'. This sole surviving tree is in Curepipe Botanical Garden in Mauritius and is thought to predate the garden. It is now over 150 years old, and needs the scaffolding and cage to support it. Photo: Paul Smith. 
(IUCN, 2020) is Robinsonia berteroi, which is endemic to Robinson Crusoe Island within the archipelago of Juan Fernández Islands, Chile (Novoa, 2020). There is currently one known living individual, which is on the top of El Yunque hill. It was recorded as more abundant in the past, therefore it is suggested that the species underwent a loss of locations and area of occupation between 1908 and 1982 due to clearing for agriculture and development. It was considered to be extinct after the previously last known individual died in 2004, prior to the discovery of another individual in 2015. Cultivation of this species is recommended for conservation. A third example is Pleodendron costaricense, a large tree endemic to Costa Rica, of which only two or three mature individuals remain (Rivers, 2019). Although the trees are flowering and fruiting, little regeneration is evident. Two trees are found along roads built for dams and logging. Due to its small population size, the species is listed as Critically Endangered. Fourthly, Hibiscus bennetti is known from a very small population of only four individuals (it is now likely that only two remain post Cyclone Winston) from a single location on Vanua Levu in Fiji (Thomson \& Linsky, 2020). The species is threatened by increasingly frequent and intense weather events such as cyclones which impact its habitat and the existing mature individuals. A final example is Croton leptanthus, which is endemic to Lasanag Island, Morobe Province, Papua New Guinea (Jimbo \& Barstow, 2020). Only one individual of this species remains on the island. The species is at risk from the expansion of home gardens and use of the forest, and requires in situ and ex situ conservation efforts that engage with the local community. It is globally assessed as Critically Endangered.

Of course, there are many examples of successful species recovery, particularly where multidisciplinary approaches have been used. Perhaps the most famous is the café marron (Ramosmania rodriguesi) from Rodrigues in the Indian Ocean (Fig. 3). This species had been reduced to a single plant left in the wild, but over the last 30 years, particularly through horticultural efforts, has been propagated (Magdalena, 2010) and successfully reintroduced into Grande Montagne National Park in Rodrigues. Another example is the Mulanje cedar (Widdringtonia whytei), Malawi's national tree (Fig. 4). In 2019, this species had just seven mature individuals left within its native range on Mount Mulanje and has since been completely extirpated due to its value as a timber species (Chanyenga et al., 2019). However, $\mathrm{BGCl}$ and partners over the last few years have set up community nurseries around Mount Mulanje to propagate the species, and, to date, over 500,000 seedlings have been reintroduced back onto the mountain. Specialist horticultural expertise was provided by Dan Luscombe from Bedgebury Pinetum in Kent (UK), who helped to set up the nurseries and trained the people managing them. A third example (Fig. 5) is the golden camellia (Camellia nitidissima), from China and Vietnam. This is another species which was reduced to just a handful of individuals. Through work with local communities, however, this very charismatic species has now been propagated not just for reintroduction and recovery, but also to sell in order to raise money and improve livelihoods in surrounding communities (Global Trees Campaign, 2021). Finally, the Chinese hat tree (Karomia gigas) from Tanzania (Fig. 6) is down to about 12 individuals and has completely gone from Kenya where it used to also occur (Lovett \& Clarke, 1998). A useful timber tree with a very straight bole, it has been cut down - together with many other species 


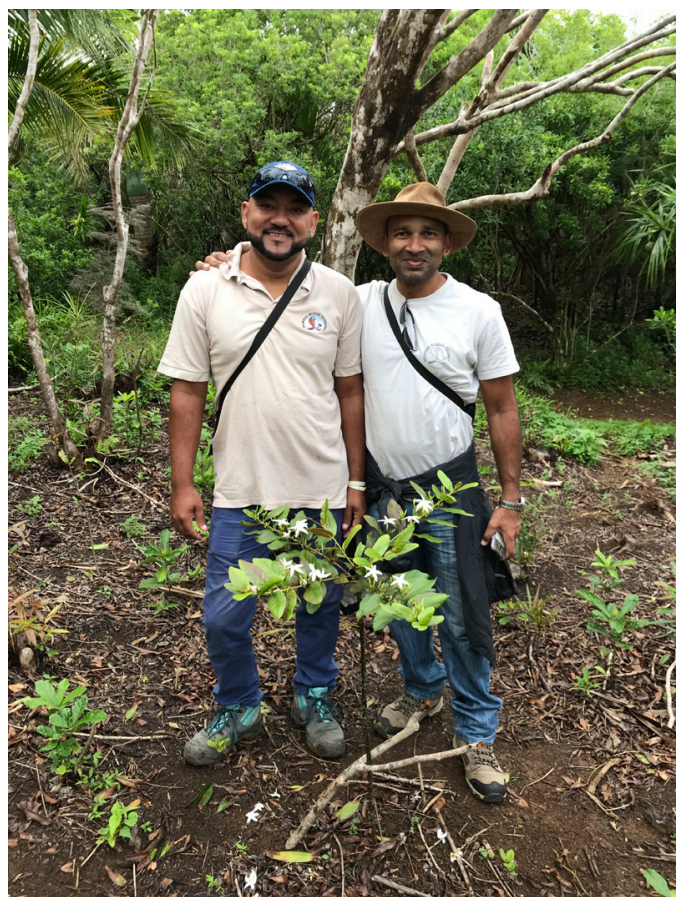

Fig. 3 Café marron (Ramosmania rodriguesi) from Rodrigues in the Indian Ocean. This species was down to a single plant left in the wild but over the last 30 years has been propagated and successfully reintroduced into Grande Montagne National Park in Rodrigues. Photo: Paul Smith.

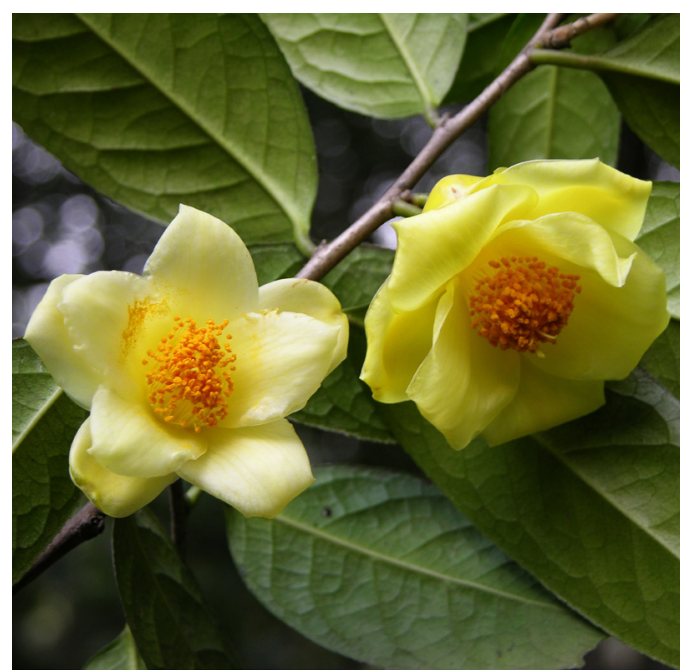

Fig. 5 Golden camellia (Camellia nitidissima) has been brought back from the brink of extinction in the wild by training local communities to propagate it and sell it, taking pressure off the remaining wild plants and generating income for local people. Photo: Ouyang Pei.

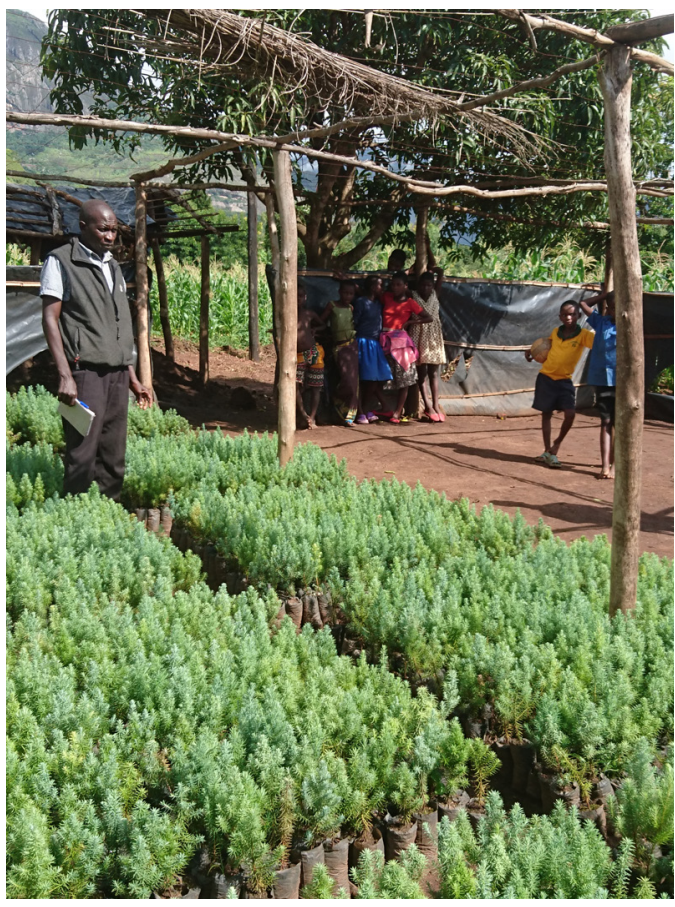

Fig. 4 Mulanje cedar (Widdringtonia whytei), Malawi's national tree, was reduced to just seven mature individuals in the wild in 2016, but $>500,000$ seedlings have now been propagated in community nurseries and reintroduced to its native range. Photo: Paul Smith.

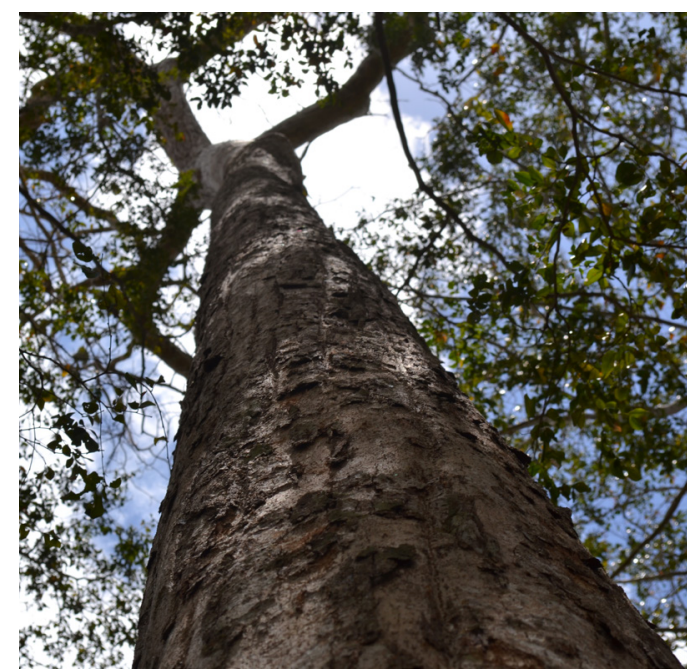

Fig. 6 Chinese hat tree (Karomia gigas), a tall, straight-boled tree of the East African Coastal Forest that has been cut down for its timber but was propagated for the first time in 2019. Photo: Kirsty Shaw, BGCl. 
- in East African coastal forests. Karomia was propagated for the first time last year by Missouri Botanical Garden (USA) working with the Tanzania Tree Seed Agency, and we are hopeful that we can help this species to recover now that we know how to germinate the seed.

\section{Impediments to employing horticultural expertise}

Many plant species are in trouble, but we have a large pool of horticultural expertise that can be deployed where it is needed. What are the impediments to deploying that expertise? Firstly, information on which species need help and where they are located is not readily available for many species. Secondly, there may be institutional impediments. For example, horticulturists are often not part of plant conservation programmes within their own organisations; in many botanical institutions, conservation is the domain of the scientists. There is also a question of priorities: botanic gardens are not always willing to deploy their horticultural expertise in this area because of competing commitments, in particular bringing in visitors, ornamental horticulture and so on. Conversely, conservation practitioners do not necessarily know where to find specialist horticultural expertise. Finally, of course, funding for travelling or staff time may not be available; institutions might be willing to let their horticulturist go and contribute to conservation work, but if there is no money for travel, then everything stops there. So what can we do at $\mathrm{BGCl}$ to help with this situation?

\section{$\mathrm{BGCl}$ tools and resources to support deployment of horticultural expertise BGCl Global Conservation Consortia}

Successful plant conservation requires a multidisciplinary approach and, to this end, $\mathrm{BGCl}$ has established Global Conservation Consortia (GCC), comprising institutions and individuals that focus on the conservation of particular taxa and bring their information, technical and social skills to bear (Westwood et al., 2020). Box 1 sets out the objectives of the Consortia and, to date, GCC have been established for Magnolia (led by Atlanta Botanical Garden, USA), oaks (led by Morton Arboretum in Lisle, IL, USA), Rhododendron (led by the Royal Botanic Garden Edinburgh, UK) and Acer (led by the University of British Columbia Botanical Garden, Canada).

\section{Box 1 Global Conservation Consortia objectives}

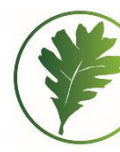

GLOBAL CONSERVATION CONSORTIUM OAK

- Establish and foster a network of experts

- Identify and prioritise species of greatest conservation concern

- Establish and manage coordinated ex situ collections of high conservation value

- Undertake and facilitate applied research (including conservation biology,
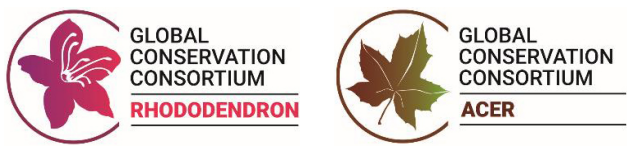

population genetics, cryotechnology, taxonomy, etc.)

- Ensure that threatened species are conserved in situ

- Build capacity to empower and mobilise in-country partners in diversity centres

- Increase public awareness and engagement 
Further GCC under development include cycads, dipterocarps and the genus Erica. The GCC focus on taxa that are challenging to conserve in seed banks, and for which extensive ex situ living collections and knowledge about propagation and management already exist in horticulture. Partner institutions comprise gardens in the north that have collections and expertise as well as gardens in the centres of diversity for the species, and the approach entails integrated conservation, building up genetically diverse living collections, and using those for reintroduction and species recovery in the wild. $\mathrm{BGCl}$ encourages botanic gardens and arboreta interested in leading GCC for particular taxa to get in touch.

\section{$B G C l$ conservation tracker tool}

When it comes to information about threatened species themselves, where they are and which ones need particular attention, $\mathrm{BGCl}$ is using Global Tree Assessment data to develop a tree conservation portal and tracker. The tracker will comprise country-level synthesis data (Fig. 7) summarising the status of ex situ and in situ tree conservation country by country, and species-level information for threatened species (Fig. 8), including information on species recovery actions in real time, i.e. who is working on what. The tracker will enable us to identify 'orphan' threatened species that are not being effectively conserved where resources need to be prioritised.

\section{BGCl Directory of Expertise}

If we know where the problem species are, and where we need to direct our efforts, how do we find the expertise? To help with this, $\mathrm{BGCl}$ has developed a Directory of Expertise ${ }^{2}$ which currently includes 11

${ }^{2}$ https://app.sheepcrm.com/bgci/teams/ different disciplines, including conservation, horticulture, ecological restoration and a number of others that are related to species recovery. We hope that, once populated with enough experts, this platform can be used to share the skills within our network with broader society, particularly with the wider conservation community. So, for example, if the Chilean authorities need to find someone with skills related to the propagation or conservation of Pacific island Asteraceae, they have a tool enabling them to search using taxonomy, geographical area of expertise and so on to find their particular expert.

\section{BGCl's Global Botanic Garden Fund}

Finally, there is the problem of funding. Working closely with the Morton Arboretum, Minnesota Landscape Arboretum and other funders, $\mathrm{BGCl}$ has set up the Global Botanic Garden Fund, ${ }^{3}$ which is a small grants programme that supports partnerships, species recovery and other botanic garden activities covered by the Global Strategy for Plant Conservation. ${ }^{4}$ In 2020, we made 40 small grants of a maximum value of US\$2,500 $(£ 1,800)$ - enough to cover travel, exchange visits, field work activities etc. We encourage you to apply for funding from the Global Botanic Garden Fund.

\section{Conclusions}

Although $\mathrm{BGCl}$ can create tools that will match the right expert with the right species, it is ultimately down to institutions to decide whether they want to get involved and where they want to get involved - and this might mean making difficult choices. Do you use your horticultural expertise to

${ }^{3}$ https://www.bgci.org/our-work/ services-for-botanic-gardens/global-botanic-garden-fund/ ${ }^{4}$ https://www.plants2020.net/ 


\section{Country Overview}

\section{Chile}

globally threatened tree species

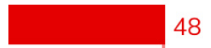

native tree species

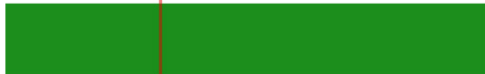
endemic tree species
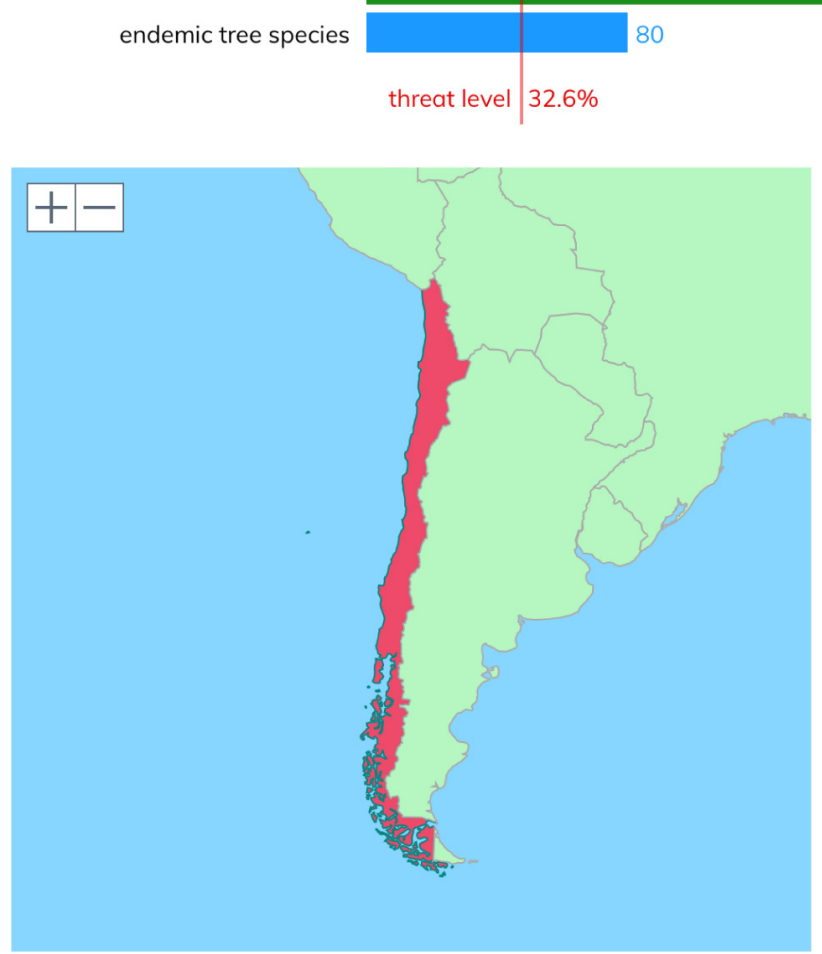

\section{Conservation Action}

124 of 147 tree species (39 globally threatened) are found in botanic garden, arboretum or seed bank ex situ collections

- 74 tree species (31 globally threatened) are found in ex situ collections in Chile

- 121 tree species (36 globally threatened) are found in ex situ collections outside of Chile

- 23 tree species (0 globally threatened) are not found in any ex situ collections

110 of 147 tree species (48 globally threatened) are found in a protected area globally (Data source: Protected Planet).

Fig. 7 Country synthesis data in BGCl's prototype tree conservation tracker tool will summarise in situ and ex situ conservation efforts for each country's tree flora, enabling gap analysis and targeting of effort and resources. 


\section{Species Overview}

\section{Paubrasilia echinata (Lam.) Gagnon, H.C.Lima \& G.P.Lewis}

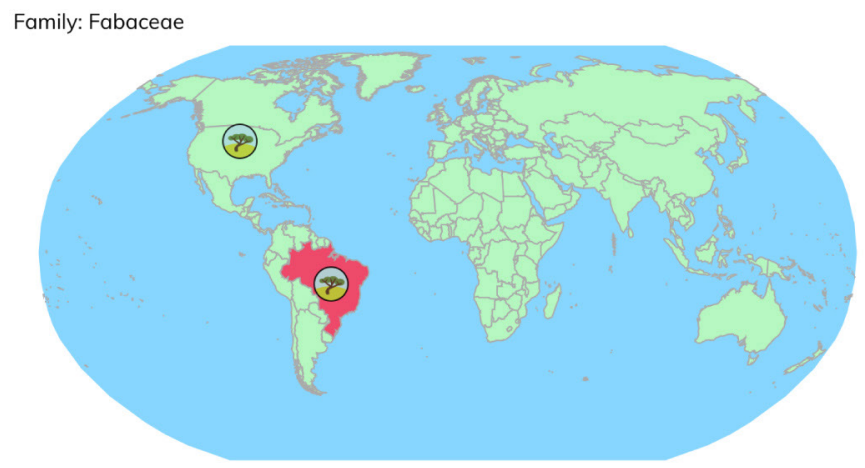

The native country distribution for the species is marked in red. The tree icon shows the country location of ex situ collections of this species.

Distribution:

(Brazil

\section{Conservation Action}

4 botanic gardens, arboreta or seed banks have this species in their ex situ collection.

- 2 collections are in the country of origin.

\section{The tree species is not known to exist in a protected area (Data source: Protected} Planet).

\section{Conservation Tracker}

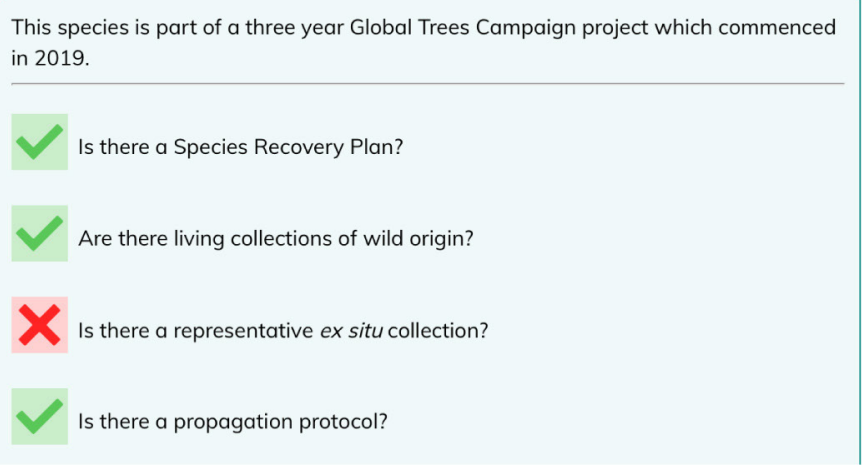

Fig. 8 Species-level information in BGCl's prototype tree conservation tracker tool will summarise in situ and ex situ conservation efforts, species by species, in real time including links to organisations actively working on the species' recovery. 
grow an interesting array of plant species within the garden and bring in visitors? Or do you deploy your horticulturists working with partners to conserve plant diversity? It is possible to do both, of course, but nevertheless, institutions will need to decide that they are going to get involved. Arguably, the choice is actually quite stark. Botanic gardens can either become museums of curiosity that show a wide range of plant species that are extinct in the wild, with the botanic garden being the only place people can see them, or they can be part of the solution to the biodiversity crisis. At $\mathrm{BGCl}$, we hope the latter is the case, and that means working with partners in biodiversity hotspots, offering training, mentorship and skills, deploying resources where they are most needed and, most of all, making sure that in situ conservation is a priority. Too often collecting expeditions have been about bolstering institutions' collections rather than conserving threatened species in situ. We need to change that emphasis and work on the recovery of these species in the wild.

\section{References}

ANTONELLI, A., FRY, C., SMITH, R.J., SIMMONDS, M.S.J., KERSEY, P.J., PRITCHARD, H.W. ET AL. (2020). State of the World's Plants and Fungi 2020. doi: https://doi.org/10.34885/172

BEECH, E., RIVERS, M., OLDFIELD, S. \& SMITH, P.P. (2017). GlobalTreeSearch: The first complete global database of tree species and country distributions. Journal of Sustainable Forestry, 36(5): 454-489. doi: https://doi.org/10.1080/10549811.2 017.1310049

CHANYENGA, T., SHAW, K. \& MITOLE, I. (2019). Widdringtonia whytei. The IUCN Red List of Threatened Species 2019. doi: https:// dx.doi.org/10.2305/IUCN.UK.2019-3.RLTS. T33216A126090798.en
DOUGLAS, G.C. (1987). Embryo culture of a rare plant Hyophorbe amaricaulis Martius (Palmae). Journal of Plant Physiology, 130(1): 73-77. doi: https://doi.org/10.1016/S0176-1617(87)80303-6

ENCYCLICAL (2018). Laudato Si' of the Holy Father Francis on Care for our Common Home. p. 25, para 33. Available online: www.vatican.va/content/ dam/francesco/pdf/encyclicals/documents/ papa-francesco_20150524_enciclica-laudato-si_ en.pdf (accessed January 2021).

GLOBAL TREES CAMPAIGN (2021). Golden Camellia. Available online: https://globaltrees.org/ threatened-trees/trees/golden-camellia/ (accessed January 2021).

HOOKE, R. LEB., MARTIN-DUQUE, J.F. \&

PADRAZA, J. (2012). Land transformation by humans: a review. GSA Today, 22(12): 4-10. doi: https://doi.org/10.1130/GSAT151A.1

IUCN (2020). The IUCN Red List of Threatened Species. Version 2020-3. Available online: www. iucnredlist.org (accessed January 2021).

JIMBO, T. \& BARSTOW, M. (2020). Croton leptanthus. The IUCN Red List of Threatened Species 2020. doi: https://dx.doi.org/10.2305/IUCN. UK.2020-2.RLTS.T142768912A143762054.en

LOVETT, J. \& CLARKE, G.P. (1998). Holmskioldia gigas. The IUCN Red List of Threatened Species 1998. doi: https://dx.doi.org/10.2305/IUCN.UK.1998. RLTS.T35173A9916244.en

MAGDALENA, C. (2010). Raising the living dead. Sibbaldia, 8: 63-73. doi: https://doi.org/10.24823/ Sibbaldia.2010.137

MOUNCE, R., SMITH, P. \& BROCKINGTON, S. (2017). Ex situ conservation of plant diversity in the world's botanic gardens. Nature Plants, 3: 795-802. doi: https://doi.org/10.1038/s41477-017-0019-3 NEWTON, A., OLDFIELD, S., RIVERS, M., MARK, J., SCHATZ, G., GARAVITO, N., CANTARELLO, E., GOLICHER, D., CAYUELA, L. \& MILES, L. (2015). Towards a Global Tree Assessment. Oryx, 49(3): 410-415. doi: https://doi.org/10.1017/ S0030605315000137

NOVOA, P. (2020). Robinsonia berteroi. The IUCN Red List of Threatened Species 2020. doi: https://dx.doi.org/10.2305/IUCN.UK.2020-1.RLTS. T158536719A158673805.en

RIVERS, M.C. (2019). Pleodendron costaricense. The IUCN Red List of Threatened Species 2019. doi: 
https://dx.doi.org/10.2305/IUCN.UK.2019-3.RLTS. T136055038A136055040.en

SMITH, P.P. (2016). Building a global system for the conservation of all plant diversity: a vision for botanic gardens and for Botanic Gardens Conservation International. Sibbaldia, 14: 5-13. doi: https://doi.org/10.24823/Sibbaldia.2016.208

SMITH, P., DICKIE, J., LININGTON, S., PROBERT, R. \& WAY, M. (2011). Making the case for plant diversity. Seed Science Research, 21(1): 1-4. doi: https://doi.org/10.1017/S0960258510000309

SMITH, P. \& HARVEY-BROWN, Y. (2018). Technical Review: The economic, social and environmental benefits of botanic gardens. Botanic Gardens Conservation International, Kew, Richmond. Available online: www.bgci.org/files/IAC/ IAC\%202018/TechReportLowRes.pdf (accessed January 2021).
THOMSON, L. \& LINSKY, J. (2020). Hibiscus bennettii. The IUCN Red List of Threatened Species 2020. doi: https://doi.org/10.2305/IUCN.UK.2020-2. RLTS.T168544255A168544282.en

VENTER, O., SANDERSON, E.W., MAGRACH, A., ALLAN, J.R., BEHER, J., JONES, K.R., POSSINGHAM, H.P., LAURANCE, W.F., WOOD, P., FEKETE, B.M., LEVY, M.A. \& WATSON, J.E.M. (2016). Sixteen years of change in the global terrestrial human footprint and implications for biodiversity conservation. Nature Communications, 7(12558). doi: https://doi.org/10.1038/ ncomms 12558

WESTWOOD, M., CAVENDER, N., MEYER, A. \& SMITH, P. (2020). Botanic garden solutions to the plant extinction crisis. Plants, People, Planet, 3(1): 22-32. doi: https://doi.org/10.1002/ppp3.10134 
